\title{
STRATEGI PENGUATAN PERENCANAAN DAN PENGANGGARAN DI PROVINSI KEPULAUAN BANGKA BELITUNG DALAM MENANGGULANGAN KEMISKINAN
}

\section{Strengthening Strategies of Planning and Budgeting for Poverty Alleviation in Bangka Belitung Province}

\author{
Novita Frahesti Ade Wijaya ${ }^{1}$, Dwi Rachmina ${ }^{2}, M^{\prime}$ mun Sarma ${ }^{3}$
}

\author{
1 Staff Badan Perencanaan Pembangunan dan Penelitian Pengembangn Daerah, \\ Provinsi Kepulauan Bangka Belitung. Email: nfawgemini@gmail.com \\ 2Staff Pengajar Departemen Agribisnis Fakultas Ekonomi dan Manajemen. IPB. Email: \\ dwirachmina@gmail.com \\ ${ }^{3}$ Staff Pengajar Departemen Manajamen, Fakultas Ekonomi dan Manajemen. IPB. Email: \\ mamun_sarma@yahoo.com
}

\begin{abstract}
The realization of the poverty level in Bangka Belitung Province from 2013 to 2015 fluctuated. The levels of poverty in 2013 and 2015 did not reach the target while that of 2014 reached it. This research aims to analyze the implementation of planning and budgeting and to formulate strategies for strengthening the planning and budgeting of Bangka Belitung Province in regards to poverty alleviation. The analyses were carried out using the qualitative and quantitative methods. This research used primary and secondary data, and the determination of samples was conducted using a purpossive sampling technique. The results of the research show that (1) the level of planning and budgeting implementation in Bangka Belitung Province in poverty alleviation in the year of 2013-2015 was moderate with low competence variable of human resource, and this needs to be improved; (2) the internal and external matrices of the governmental policy of Bangka Belitung Provincial in supporting poverty alleviation with weighted score data of 2.354 and 3.055 were in quadrant II that is grow and build through intensive and integrated strategy; (3) the main strategy that must be implemented is to improve the support of local and central government policies in human resources development and planner apparatus to facilitate poverty alleviation. Implementation that can be conducted is the capacity building program of the planner apparatus for the period of 2018-2022.
\end{abstract}

Keywords: integrated strategy, intensive strategy, implementation level, poverty

ABSTRAK
Realisasi tingkat kemiskinan di Provinsi Kepuluan Bangka Belitung dari tahun 2013-2015 bersifat
fluktuatif. Tingkat kemiskinan tahun 2013 dan 2015 tidak mencapai target, sedangkan tahun 2014
telah mencapai target. Penelitian ini menggunakan data primer dan sekunder. Penentuan sampel
dipilih secara sengaja. Metode analisis yang digunakan adalah kualitatif dan kuantitatif. Hasil
penelitian menunjukkan bahwa (1) tingkat implementasi perencanaan dan penganggaran di
Provinsi Kepulauan Bangka Belitung dalam penanggulangan kemiskinan tahun 2013-2015 adalah
sedang dengan variabel kompetensi SDM rendah dan masih harus dilakukan perbaikan; (2)
matriks internal dan eksternal kebijakan Pemerintah Provinsi Kepulauan Bangka Belitung dalam
mendukung penanggulangan kemiskinan dengan data skor terbobot 2.354 dan 3.055 berada pada
kuadran II grow and build melalui strategi intensif dan terintegrasi; (3) strategi utama yang harus
dilaksanakan adalah meningkatkan dukungan kebijakan Pemerintah Daerah dan Pusat dalam
pembinaan dan pengembangan SDM aparatur perencana untuk mempermudah penanggulangan
kemiskinan. Implementasi yang dapat dilaksanakan adalah program peningkatan kapasitas
sumber daya aparatur perencana selama tahun 2018-2022.
Kata kunci : strategi intensif, strategi terintegrasi, tingkat implementasi, kemiskinan




\section{PENDAHULUAN}

Isu kemiskinan sangat aktual dari masa ke masa. Hal ini diamanatkan dalam Sustainable Development Goals (SDGs) tahun 2016-2030. Menurut Papilaya (2013), secara faktual kemiskinan di Indonesia merupakan suatu permasalahan mendasar dalam pembangunan di Indonesia. Salah satu isu yang diangkat dalam pembangunan Provinsi Kepulauan Bangka Belitung adalah kemiskinan. Secara nasional target tingkat kemiskinan yang dicanangkan Pemerintah Pusat dalam Rencana Pembangunan Jangka Menengah Nasional (RPJMN) tahun 2015-2019 sebesar 8.0-7.0 persen pada tahun 2019 (Bappenas 2015). Di Provinsi Kepulauan Bangka Belitung target tingkat kemiskinan berdasarkan Rencana Pembangunan Jangka Menengah Daerah (RPJMD) Tahun 2012-2017 adalah 3.02.4 persen pada tahun 2017 (Bappeda 2012).

Setiap tahun target tingkat kemiskinan dijabarkan lagi ke dalam Rencana Kerja Pembangunan Daerah (RKPD). Tahun 2015 target tingkat kemiskinan dalam RKPD Provinsi Kepulauan Bangka Belitung adalah 3.60 persen (Bappeda 2014). Kenyataannya pada tahun 2015 tingkat kemiskinan sebesar 5.41 persen dibandingkan dengan tingkat kemiskinan tahun 2014 sebesar 4.97 persen. Berarti persentase kenaikannya sebesar 0.44 persen (BPS 2015). Padahal, Pemerintah Daerah telah menanggulangi kemiskinan dengan 37 program yang dilaksanakan 15 Satuan Perangkat Kerja Daerah (SKPD) sebagai penanggung jawabnya.

Berdasarkan Tabel 1, menunjukkan bahwa realisasi tingkat kemiskinan Provinsi Kepulauan Bangka Belitung dari tahun 2013-2015 bersifat fluktuatif. Tingkat kemiskinan tahun 2013 dan 2015 tidak mencapai target, sedangkan tahun 2014 telah mencapai target. Di Provinsi Kepulauan Bangka Belitung, BPS dalam mengukur jumlah dan pesentase penduduk miskin menggunakan konsep kemampuan memenuhi kebutuhan dasar (basic need approach). Melalui pendekatan ini, kemiskinan dipandang sebagai ketidakmampuan dari sisi ekonomi untuk memenuhi kebutuhan dasar makanan dan bukan makanan yang diukur dari sisi pengeluaran (BPS 2015).

Menurut World Bank (2006), kemiskinan dari segi bukan makanan adalah masalah serius dibandingkan dengan kemiskinan dari segi makanan. Kemiskinan dari segi makanan bersifat jangka pendek, sedangkan kemiskinan dari segi non makanan bersifat jangka panjang. Program penanggulangan kemiskinan di Provinsi Kepulauan Bangka Belitung didukung oleh Anggaran Pendapatan Belanja Daerah (APBD) melalui belanja langsung SKPD.

Tabel 1 Perkembangan APBD dan kemiskinan Provinsi Kepulauan Bangka Belitung Tahun 2013-2015

\begin{tabular}{ccccc}
\hline Tahun & $\begin{array}{c}\text { APBD } \\
\text { (miliar rupiah) }\end{array}$ & $\begin{array}{c}\text { Belanja Langsung } \\
\text { Program Penanggulangan Kemiskinan } \\
\text { (miliar rupiah) }\end{array}$ & $\begin{array}{c}\text { Target } \\
\text { Tingkat } \\
\text { Kemiskinan }\end{array}$ & $\begin{array}{c}\text { Realisasi } \\
\text { Tingkat } \\
\text { Kemiskinan }\end{array}$ \\
\hline 2013 & $3.391,75$ & 101,42 & 4.60 & 5.25 \\
2014 & $3.646,80$ & 75,50 & 4.98 & 4.97 \\
2015 & $4.144,43$ & 107,18 & 3.60 & 5.41 \\
\hline
\end{tabular}

Sumber : Bappeda Provinsi Kepulauan Bangka Belitung tahun 2016

Menurut Haryanto (2008), salah satu prinsip dalam penganggaran adalah value for money. Tiga elemen dalam konsep value for money yaitu ekonomi dalam pengadaan dan alokasi sumber daya, efesien (berdaya guna) dalam penggunaan sumber daya dalam arti penggunaannya diminimalkan, serta 
efektif (berhasil guna) dalam arti mencapai tujuan dan sasaran. Program dan anggaran di Provinsi Kepulauan Bangka Belitung telah diupayakan, namun belum efektif dalam pelaksanaannya terhadap penurunan tingkat kemiskinan yang dicanangkan Pemerintah Daerah sesuai dengan target. Artinya secara umum program dan anggaran di SKPD belum mampu menyelesaikan masalah-masalah yang ada.

Pelaksanaan program diasumsikan berhubungan dengan belum efektif perencanaan dan penganggaran di Provinsi Kepulauan Bangka Belitung dalam penanggulangan kemiskinan. Perencanaan dan penganggaran yang memihak orang miskin (pro poor) adalah kegiatan-kegiatan pengambilan keputusan dari sejumlah pilihan mengenai sasaran dan cara-cara yang akan dilaksanakan di masa depan dan proses penyusunan rencana keuangan guna mencapai tujuan yang diinginkan, yaitu penanggulangan kemiskinan, serta pemantauan dan penilaian atas perkembangan hasil pelaksanaannya, yang akan dilakukan secara sistematis dan berkesinambungan (Akhmadi 2005). Selanjutnya Sjafrizal (2009) berpendapat bahwa implikasi dari keberhasilan pembangunan daerah tidak lepas dari optimalisasi aspek perencanaan dan penganggaran.

Upaya penanggulangan kemiskinan, perlu dilakukan langkahlangkah dan pendekatan yang sistematik, terpadu dan menyeluruh dalam koordinasi antar pelaku lintas program dalam penyiapan rumusan dan penyelenggaraan penanggulangan kemiskinan. Oleh karena itu, agar semua pihak dapat berperan aktif dalam penanggulangan kemiskinan melalui perencanaan dan penganggaran yang lebih baik untuk tahun berikutnya sebagai persoalan mendasar dan menjadi fokus dalam upaya penanggulangan

16 kemiskinan.
Berdasarkan uraian di atas, maka tujuan dari penelitian ini adalah:

1. Menganalisis implementasi perencanaan dan penganggaran di Provinsi Kepulauan Bangka Belitung dalam penanggulangan kemiskinan.

2. Merumuskan dan menyusun strategi yang tepat dalam penguatan perencanaan dan penganggaran di Provinsi Kepulauan Bangka Belitung dalam penanggulangan kemiskinan.

\section{METODOLOGI}

\section{Jenis dan Sumber Data}

Penelitian ini dilakukan di Provinsi Kepulauan Bangka Belitung pada bulan Maret sampai Mei 2017. Jenis data yang digunakan dalam penelitian ini terdiri dari data primer dan sekunder. Data primer diperoleh dengan cara observasi dan penyebaran kuesioner. Data sekunder berasal dari studi pustaka dan kajian terhadap litelatur terkait. Penentuan sampel berdasarkan purposive sampling. SKPD tersampel terdiri dari BPMPD, DINDIK, DINKESOS, DISTANBUNAK, dan DISNAKERTRANS. Selanjutnya responden tersampel terdiri dari Sekretaris Daerah, Kepala SKPD, Kepala Bidang SKPD, Kepala Sub Bidang Perencanaan SKPD, Anggota DPRD, dan Ketua Advokasi TNP2K.

\section{Metode Analisis Data}

Dalam penelitian ini alat analisis yang digunakan sesuai dengan tujuan dalam penelitian ini adalah :

1. Kuantitatif dengan skala likert.

2. Analisis SWOT dan QSPM.

Pada penelitian ini untuk mendapatkan data kuantitatif digunakan skala likert. Menurut Sugiyono (2009), skala likert digunakan untuk mengukur sikap, pendapat, dan persepsi sesorang atau sekelompok tentang fenomena sosial. Skala likert dilakukan melalui 
pengisian kuesioner oleh responden. Penentuan skor menggunakan skala penilaian 1-4. Pengolahan data akan dilakukan dengan melakukan klasifikasi jawaban ke dalam kelas interval yang dinayatakan dalam bentuk skor yang diolah dari perhitungan skala likert.

Analisis SWOT dilakukan untuk menentukan faktor yang menjadi kekuatan dan kelemahan serta peluang dan ancaman dalam penguatan perencanaan dan penganggaran di Provinsi Kepulauan Bangka Belitung dalam penanggulangan kemiskinan menggunakan analisis Internal Faktor Evaluation (IFE) dan External Faktor Evaluation (EFE). Analisis SWOT dilakukan melalui pengisian kuesioner oleh Sekda, Ka. SKPD, Anggota DPRD, dan Ketua Advokasi TNP2K. Penentuan bobot dilakukan dengan mengajukan identifikasi faktor internal dan ekternal pada stakeholder dengan menggunakan metode paired comparison (Kinnear dan Taylor 1991).

Penggunaan analisis QSPM bertujuan untuk memperoleh prioritas strategi terbaik yang paling menarik untuk diimplementasikan sesuai dengan arah dan kebijakan Pemerintah Provinsi Kepulauan Bangka Belitung dalam hal perencanaan dan penganggaran. Analisis QSPM menggunakan skor daya tarik atau Attractiveness Score (AS) dengan nilai daya tarik adalah $1=$ tidak menarik, $2=$ agak menarik, $3=$ cukup menarik, $4=$ sangat menarik. Nilai Total Attractiveness Score (TAS) tertinggi menandakan strategi yang paling layak untuk diimplementasikan dengan memperhatikan seluruh faktor internal dan eksternal (David 2015).

\section{HASIL DAN PEMBAHASAN}

\section{Implementasi Perencanaan dan Penganggaran di Provinsi Kepulauan Bangka Belitung dalam Penanggulangan Kemiskinan}

Mekanisme Implementasi perencanaan dan penganggaran di Provinsi Kepulauan Bangka Belitung dalam penanggulangan kemiskinan untuk menjawab tujuan penelitian yang pertama. Pelaksanaan perencanaan dan penganggaran di Provinsi Kepulauan Bangka Belitung dalam penanggulangan kemiskinan berserta variabel-variabelnya meliputi komitmen pimpinan, kompetensi SDM, sistem administrasi perencanaan dan penganggaran, kesesuaian perencanaan dan penganggaran, penghargaan (reward), dan sanksi (punishment). Berdasarkan hasil analisis skala likert terhadap keenam variabel, maka secara keseluruhan hasil dari setiap variabel tersebut disajikan pada Tabel 2.

Tabel 2 Persepsi responden terhadap implementasi perencanaan dan penganggaran di Provinsi Kepulauan Bangka Belitung dalam penanggulangan kemiskinan tahun 2013-2015

\begin{tabular}{clcc}
\hline No & \multicolumn{1}{c}{ Variabel } & Skor Total & Kategori \\
\hline 1. & Komitmen pimpinan & 428 & Tinggi \\
2. & Kompetensi SDM & 345 & Rendah \\
3. & Sistem administrasi perencanaan dan & 234 & Sedang \\
& $\begin{array}{l}\text { penganggaran } \\
\text { 4. }\end{array}$ & & \\
& Kesesuaian perencanaan dan & 342 & Sedang \\
5. & Penganggaran & 149 & Tinggi \\
6. & Sanksi (punishment) & 142 & Tinggi \\
\hline & Total & 1640 & Sedang \\
\hline
\end{tabular}




\begin{tabular}{ccrrllr}
\hline Hasil & perolehan & skor & total & & \multicolumn{2}{c}{ Startegi Penguatan Perencanaan dan } \\
menunjukkan & \multicolumn{2}{c}{ bahwa } & tingkat & & Penganggaran di Provinsi Kepulauan \\
implementasi & perencanaan & dan & & Bangka & Belitung & dalam \\
penganggaran & di $\begin{array}{c}\text { Provinsi } \\
\text { Kepulauan }\end{array}$ & & Penanggulangan Kemiskinan &
\end{tabular}

Bangka Belitung dalam penanggulangan kemiskinan tahun 2013-2015 adalah sedang dan masih diperlukan perbaikan di masa mendatang. Dari keenam variabel tersebut, kompetensi SDM rendah dengan beberapa indikator yang belum berjalan baik. Hal ini disebabkan keterbatasan tingkat pendidikan, jumlah staf perencanaan, pengetahuan tentang anggaran berbasis kinerja (ABK), keikutsertaan dalam sosialisasi dan pelatihan, serta anggaran pengembangan SDM. Keterbatasan ini akan berdampak kepada implementasi perencanaan dan penganggaran dalam penanggulangan

\section{Identifikasi Faktor Kunci Internal dan Eksternal}

Berdasarkan hasil penyebaran kuesioner yang dilakukan dengan responden, maka diperoleh 18 faktor strategis yang berperan dalam penguatan perencanaan dan penganggaran di Provinsi Kepulauan Bangka Belitung dalam penanggulangan kemiskinan. Hasil penilaian atas faktor internal dan eksternal menggunakan Internal Factor Evaluation (IFE) dan External Faktor Evaluation (EFE) disajikan dalam Tabel 3 dan 4.

Tabel 3 Analisis IFE penguatan perencanaan dan penganggaran di Provinsi Kepulauan Bangka Belitung dalam penanggulangan kemiskinan

\begin{tabular}{|c|c|c|c|c|}
\hline No & Kekuatan & Bobot & Rating & Skor \\
\hline 1. & $\begin{array}{l}\text { Kebijakan Pemerintah Daerah dalam mendukung } \\
\text { penanggulangan kemiskinan yang jelas }\end{array}$ & 0.117 & 3.86 & 0.453 \\
\hline 2. & $\begin{array}{l}\text { Komitmen pimpinan SKPD terkait penanggulangan } \\
\text { kemiskinan yang tinggi }\end{array}$ & 0.131 & 3.71 & 0.486 \\
\hline 3. & Struktur organisasi dan tupoksi SKPD yang jelas & 0.094 & 3.14 & 0.297 \\
\hline 4. & $\begin{array}{l}\text { Peran TAPD dan legislatif dalam perencanaan dan } \\
\text { penganggaran yang tinggi }\end{array}$ & 0.125 & 3.86 & 0.484 \\
\hline
\end{tabular}

\begin{tabular}{|c|c|c|c|c|}
\hline \multicolumn{4}{|c|}{ Total Kekuatan } & \multirow{2}{*}{1.720} \\
\hline No & Kelemahan & & & \\
\hline 1. & $\begin{array}{l}\text { Kualitas dan kuantitas aparatur perencanaan di SKPD masih } \\
\text { rendah }\end{array}$ & 0.105 & 1.29 & 0.135 \\
\hline 2. & $\begin{array}{l}\text { Pengembangan SDM aparatur perencanaan oleh Pemerintah } \\
\text { Daerah masih kurang memadai }\end{array}$ & 0.092 & 1.14 & 0.105 \\
\hline 3. & $\begin{array}{l}\text { Anggaran SKPD dalam meningkatkan kapasitas aparatur } \\
\text { perencanaan masih terbatas }\end{array}$ & 0.087 & 1.14 & 0.100 \\
\hline 4. & Tenaga fungsional perencana yang handal masih terbatas & 0.083 & 1.14 & 0.095 \\
\hline 5. & Mutasi/perputaran pejabat perencanaan sering terjadi & 0.082 & 1.14 & 0.093 \\
\hline \multirow[t]{3}{*}{6.} & SOP tertulis terkait perencanaan dan penganggaran belum ada & 0.083 & 1.29 & 0.106 \\
\hline & Total Kelemahan & & & 0.634 \\
\hline & Total keseluruan & & & 2.354 \\
\hline
\end{tabular}

Hasil perhitungan IFE (Tabel 3), menunjukkan bahwa komitmen pimpinan SKPD terkait penanggulangan kemiskinan yang tinggi sebagai kekuatan 18 utama bagi Pemerintah Provinsi Kepulauan Bangka Belitung dengan nilai tertimbang paling tinggi sebesar 0.486 .
Berdasarkan perhitungan faktor kelemahan, kualitas dan kuantitas aparatur perencanaan di SKPD masih rendah menjadi kelemahan bagi Pemerintah Provinsi Kepulauan Bangka Belitung dengan nilai tertimbang 0.135 . Kualitas dan kuantitas aparatur 
perencanaan di SKPD masih rendah

berdasarkan analisis $G A P$.

sesuai dengan hasil yang diperoleh

Tabel 4 Analisis EFE Penguatan Perencanaan dan Penganggaran Di Provinsi Kepulauan Bangka Belitung Dalam Penanggulangan Kemiskinan

\begin{tabular}{clccc}
\hline No & \multicolumn{1}{c}{ Peluang } & Bobot & Rating & Skor \\
\hline 1. & $\begin{array}{l}\text { Peraturan Pemerintah Pusat tentang sistem perencanaan dan } \\
\text { penganggaran yang jelas }\end{array}$ & 0.114 & 3.86 & 0.438 \\
2. & $\begin{array}{l}\text { Kebijakan Permenkeu Nomor 56/PMK.02/2005 tentang } \\
\text { penerapan sistem anggaran berbasis kinerja yang jelas }\end{array}$ & 0.119 & 4.00 & 0.474 \\
3. $\begin{array}{l}\text { Evaluasi TNP2K terkait pelaksanaan program } \\
\text { penanggulangan kemiskinan setiap tahun }\end{array}$ & 0.139 & 3.86 & 0.536 \\
Kebijakan Pemerintah Pusat terkait pengangkatan SDM & 0.115 & 3.71 & 0.426 \\
menjadi pejabat fungsional perencana yang jelas \\
$\begin{array}{l}\text { Bimbingan teknis dalam perencanaan dan penganggaran dari } \\
\text { K/L yang memadai }\end{array}$
\end{tabular}

Tabel 4, menunjukkan bahwa faktor evaluasi TNP2K terkait pelaksanaan program penanggulangan kemiskinan setiap tahun merupakan faktor peluang utama dengan skor tertinggi yaitu 0.536. Faktor ancaman yaitu indikator utama yang dikeluarkan oleh TNP2K kurang relevan merupakan ancaman dengan nilai tertimbang sebesar 0.469 . Evaluasi dan indikator utama dari TNP2K berpengaruh kepada perencanaan dan penganggaran di Provinsi Kepulauan Bangka Belitung dalam penanggulangan kemiskinan.

Hasil analisis matriks internal dan ekternal yang mempengaruhi perencanaan dan penganggaran di Provinsi Kepulauan Bangka Belitung dalam penanggulangan kemiskinan diperoleh skor IFE $=2.354$ dan $\mathrm{EFE}=$ 3.055. Hal ini menunjukkan bahwa strategi yang tepat adalah tumbuh dan membangun (grow and build) pada kuadran II. Strategi-strategi yang cocok adalah startegi intensif atau strategi terintegrasi.

Strategi intensif dan terintegrasi dalam penguatan dan perencanaan merupakan cara terbaik saat ini. Berdasarkan latar belakang kajian ini, ada baiknya kegiatan peningkatan SDM. Organisasi untuk mencapai tujuannya memerlukan SDM dalam perencanaan dan penganggaran dalam penanggulangan kemiskinan. Agar tujuan dapat berjalan dengan baik tentu pengelolan SDM harus dilakukan secara intensif dan terintegrasi sebagaimana tersaji pada Gambar 1. 
Skor Total IFE

2.354

\begin{tabular}{|c|c|c|c|c|}
\hline & & $\begin{array}{c}\text { Kuat } \\
3.00-4.00\end{array}$ & $\begin{array}{l}\text { Sedang } \\
2.00-2.99\end{array}$ & $\begin{array}{c}\text { Lemah } \\
1.00-1.99\end{array}$ \\
\hline 3.055 & Tinggi $3.00-4.00$ & $\begin{array}{c}\text { I } \\
\text { Grow and Build }\end{array}$ & $\begin{array}{l}\text { II } \\
\text { Grow and } \\
\text { Build }\end{array}$ & $\begin{array}{l}\text { III } \\
\text { Hold and } \\
\text { Maintain }\end{array}$ \\
\hline & Sedang $2.00-2.99$ & $\begin{array}{c}\text { IV } \\
\text { Grow and Build }\end{array}$ & $\begin{array}{l}\mathrm{V} \\
\text { Hold and } \\
\text { Maintain }\end{array}$ & $\begin{array}{c}\text { VI } \\
\text { Harvest and } \\
\text { Divestiture }\end{array}$ \\
\hline & Rendah $1.00-1.99$ & $\begin{array}{l}\text { VII } \\
\text { Hold and } \\
\text { Maintain }\end{array}$ & $\begin{array}{c}\text { VIII } \\
\text { Harvest and } \\
\text { Divestiture }\end{array}$ & $\begin{array}{c}\text { IX } \\
\text { Harvest and } \\
\text { Divestiture }\end{array}$ \\
\hline
\end{tabular}

Gambar 1 Matriks IE yang mempengaruhi perencanaan dan penganggaran di Provinsi Kepulauan Bangka Belitung dalam penanggulangan kemiskinan

\section{Perumusan Alternatif Strategi Melalui Analisis SWOT}

Dalam menentukan alternatif strategi dan keterkaitan antar strategi, maka perlu dilakukan interaksi kombinasi strategi internal maupun ekternal. Rumusan alternatif strategi yang dilakukan sesuai dengan mengacu pada tujuan perencanaan dan penganggaran di Provinsi Kepulauan Bangka Belitung dalam penanggulangan kemiskinan. Adapun perumusan strategi disusun berdasarkan faktor internal serta faktor eksternal ke dalam matriks SWOT seperti disajikan pada Tabel 6.

\section{Perumusan Strategi Prioritas melalui Quantitative Strategic Planning Matrix (QSPM)}

Berdasarkan hasil analisis QSPM pada Tabel 5, maka dapat disimpulkan bahwa jumlah nilai tertinggi atas TAS pada strategi nomor dua dengan nilai 7.52. Strategi yang layak untuk Pemerintah Provinsi Kepulauan Bangka Belitung adalah "Meningkatkan dukungan kebijakan Pemerintah Daerah dan Pusat dalam pengembangan dan pembinaan SDM aparatur perencana untuk mempermudah penanggulangan kemiskinan".

\section{Tabel 5 Hasil analisis QSPM}

\begin{tabular}{clcc}
\hline No. & \multicolumn{1}{c}{ Strategi } & Nilai TAS & Peringkat \\
\hline 1. & $\begin{array}{l}\text { Meningkatkan sinkronisasi kebijakan Pemerintah Daerah } \\
\text { dengan peraturan Pemerintah Pusat tentang penerapan }\end{array}$ & 6.41 & 4 \\
penganggaran kinerja dalam penanggulangan kemiskinan \\
2. $\begin{array}{l}\text { Meningkatkan dukungan kebijakan Pemerintah Daerah } \\
\text { dan Pusat dalam pengembangan dan pembinaan SDM } \\
\text { aparatur perencana untuk mempermudah penanggulangan }\end{array}$ & 7.52 & 1 \\
kemiskinan & & 2 \\
Meningkatkan komitmen SKPD yang kuat dalam \\
memanfaatkan data dan indikator utama kemiskinan
\end{tabular}




\section{Tabel 6 Matrik SWOT dan alternatif strategi dalam penguatan perencanaan dan penganggaran di Provinsi Kepulauan Bangka Belitung dalam penanggulangan kemiskinan}






\section{Perancangan Program}

Untuk pelaksanaan strategi utama diperlukan acuan sehingga pelaksanaannya lebih mudah untuk dilakukan. Perlu disusun kebijakan operasional, sehingga menjadi arahan dalam melaksanakan program dan kegiatan. Perancangan program dan kegiatan disajikan pada Tabel 7.

Tabel 7 Implementasi Strategi Penguatan Perencanaan dan Penganggaran di Provinsi Kepulauan Bangka Belitung Dalam Penanggulangan Kemiskinan

\begin{tabular}{|c|c|c|c|c|c|}
\hline Strategi & Program & & Kegiatan & Sasaran & $\begin{array}{c}\text { Waktu } \\
\text { Pelaksanaan }\end{array}$ \\
\hline $\begin{array}{l}\text { Meningkatkan } \\
\text { dukungan } \\
\text { kebijakan } \\
\text { Pemerintah } \\
\text { Daerah dan } \\
\text { Pusat dalam } \\
\text { pembinaan dan } \\
\text { pengembangan } \\
\text { SDM aparatur } \\
\text { perencana } \\
\text { untuk } \\
\text { mempermudah } \\
\text { penanggulangan } \\
\text { kemiskinan }\end{array}$ & $\begin{array}{l}\text { Peningkatan } \\
\text { kapasitas } \\
\text { sumber daya } \\
\text { aparatur } \\
\text { perencana }\end{array}$ & 1 & 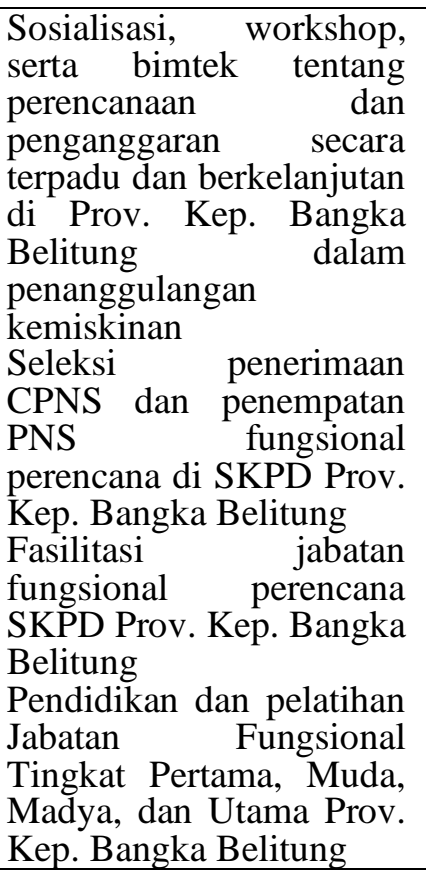 & $\begin{array}{l}\text { PNS Prov. } \\
\text { Kep. Babel } \\
\text { PNS Prov. } \\
\text { Kep. Babel }\end{array}$ & 2018-2022 \\
\hline
\end{tabular}

\section{SIMPULAN DAN SARAN}

\section{Simpulan}

Dari hasil penelitian dan pembahasan yang disampaikan, maka dapat disimpulkan beberapa hal sebagai berikut :

1. Implementasi perencanaan dan penganggaran di Provinsi Kepulauan Bangka Bangka Belitung dalam penanggulangan kemiskinan tahun 2013-2015 adalah sedang dengan variabel kompetensi SDM rendah dan masih perlu perbaikan dimasa mendatang.

2. Beberapa faktor yang mempengaruhi perencanaan dan penganggaran di Provinsi Kepulauan Bangka Belitung yaitu faktor internal dan eksternal dengan data skor terbobot 2.354 dan
3.055 berada pada kuadran II yaitu grow and build melalui strategi intensif dan strategi terintegrasi.

3. Strategi utama dan layak diimplementasikan oleh Pemerintah Provinsi Kepulauan Bangka Belitung adalah meningkatkan dukungan kebijakan Pemerintah Daerah dan Pusat dalam pembinaan dan pengembangan SDM aparatur perencana untuk mempermudah penanggulangan kemiskinan. Hasil ini membuktikan bahwa faktor SDM berperan dalam perencanaan dan penganggaran di Provinsi Kepulauan Bangka Belitung dalam penanggulangan kemiskinan. Oleh karena itu, strategi prioritas mengedepankan pembinaan dan pengembangan SDM aparatur 
perencana dalam berbentuk kegiatan dengan waktu pelaksanaan jangka menengah tahun 2018-2022.

\section{Saran}

Beberapa hal yang dapat disampaikan sebagai saran antara lain :

1. Melaksanakan program peningkatan kapasitas sumber daya aparatur perencana dalam berbagai bentuk kegiatan.

2. Melaksanakan strategi penguatan perencanaan dan penganggaran di Provinsi Kepulauan Bangka Belitung dalam penanggulangan kemiskinn yang telah dirumuskan dalam penelitian ini.

3. Perlu diukur tingkat efesiensi perencanaan dan penganggaran di Provinsi Kepulauan Bangka Belitung dalam penanggulangan kemiskinan.

\section{DAFTAR PUSTAKA}

Akhmadi. 2005. Perencanaan dan Penganggaran Strategi Penanggulangan Kemiskinan di Daerah. Lembaga Penelitian Smeru. Jakarta (ID).

[BAPPEDA] Badan Perencanaan Pembangunan Daerah. 2012. Rencana Pembangunan Jangka Panjang Menengah Provinsi Kepulauan Bangka Belitung Tahun 2012-2017.

Bappeda. Pangkalpinang (ID).

[BAPPEDA] Badan Perencanaan Pembangunan Daerah. 2014. Rencana Kerja Pemerintah Daerah Provinsi Kepulauan Bangka Belitung Tahun 2015. Bappeda. Pangkalpinang (ID).

[BAPPEDA] Badan Perencanaan Pembangunan Daerah. 2016. Rencana Kerja Pemerintah Daerah Provinsi Kepulauan Bangka
Belitung Tahun 2017. Bappeda. Pangkalpinang (ID).

[BAPPENAS] Badan Perencanaan Pembangunan Nasional. 2009. Pedoman Evaluasi Kinerja Pembangunan Sektoral. Bappenas. Jakarta (ID).

[BAPPENAS] Badan Perencanaan Pembangunan Nasional. 2015. Rencana Pembangunan Jangka Panjang Menengah Nasional Tahun 2015-2019. Bappenas. Jakarta (ID).

[BPS] Badan Pusat Statistik. 2015. Indikator Sosial 2015 Provinsi Kepulauan Bangka Belitung. BPS. Pangkalpinang (ID).

[BPS] Badan Pusat Statistik. 2015. Berita Resmi Statistik Provinsi Kepulauan Bangka Belitung. No. 64/09/19/Tahun XIII.

David, FR. 2015. Strategic Management: Concepts and Cases. 15th Ed. Essex (GB): Pearson Education Limited.

Haryanto. 2008. Perencanaan dan Penganggaran Daerah Pendekatan Kinerja. Universitas Diponegoro. Semarang (ID).

Kinnear TC, Taylor JR. 1991. Riset Pemasaran. Terjemahan Yohanes Lamarto. Erlangga. Jakarta (ID).

Papilaya, CE. 2013. Percepatan Pengurangan Kemiskinan dan Pemiskinan Bangsa. IPB Press. Bogor (ID).

Sjafrizal. 2009. Tehnik Praktis Penyusunan Perencanaan Pembangunan Daerah. Baduose Media. Jakarta (ID).

Sugiyono. 2009. Metode Penelitian Kualitatif dan $R \& D$. Alfabeta. Bandung (ID).

World Bank. 2006. Era Baru dalam Pengentasan Kemiskinan di Indonesia. World Bank. Jakarta (ID). 